$\Phi=E_{-\infty}$

\title{
Pattern of female child mortality among women in raebareli : an explanation through probability model
}

\author{
Krishna Kumar Pandey ${ }^{1}$, Pradip Kumar ${ }^{1 *}$, Ram Dular Singh ${ }^{2}$ \\ ${ }^{1}$ Research Scholar, Department of Statistics, Banaras Hindu University, Varanasi-221005, UP \\ ${ }^{2}$ Professor, Department of Statistics, Banaras Hindu University, Varanasi-221005, UP \\ *Corresponding author E-mail: pradipstats@gmail.com
}

\begin{abstract}
One of the principal determinants of population growth is mortality. The level of female child mortality is often taken as indicator of health conditions, but these may be in general regarded as an indicator of the development of a society and an important indicator of overall development of a country. In this paper, the probability model for number of female child death among women, have been derived. The application of the model in the paper is illustrated through its application to the data from Raebareli district of Uttar Pradesh from Concurrent Assessment of Health \& Family Welfare Programs and Technical Support to District of Uttar Pradesh (CATA, 2005-06). The models are estimated on the basis of observed set of data and are tested for their suitability.
\end{abstract}

Keywords: Female Child Death; Women and Probability Model.

\section{Introduction}

Sex is a key variable for disaggregation of childhood mortality rate estimates, both for monitoring and analytical purposes (Sawyer 2012). Female disadvantage in child mortality has been a subject of particular interest for researchers dealing with demography, epidemiology, public health and sociology (Arokiasamy 2004). The phenomenon of excess female mortality at certain ages is clearly present-or has been present-in a very large part of the developing world (Tabutin et al. 1995). The under-five female mortality rate, also denoted in the literature as female U5FMR, is the probability of female dying between birth and exact age 5 year. Previous studies showed that the lack of sufficient female education can be a major cause to child and infant in developing countries (Cutler et al. 2006; Papageorgiou et al. 2008). The study of female child mortality is useful for evaluating future demographic condition as well as determining the future prospects of potential changes in female population. The level of infant and child mortality is often taken as indicator of health conditions, but these may be in general regarded as an indicator of the development of a society and an important indicator of overall development of a country.

The illustration of mortality data via a parametric model has attracted the attention of actuaries, statisticians and demographers for over many decades. Study suggested an approach for estimating child mortality from all births which have taken place in last five (Hill et al. 1989). On the other hand, the estimate obtained through this method also suffers from the problem of under reporting (Pathak et al. 1991). An attempt has been made to present through linear model approach to mortality graduation, and provide arguments in their favor (Renshaw 1991).

Pandey (Pandey et al. 2016) illustrated probability model for estimating under-five mortality among women for fixed parity. Heligman (Heligman et al. 1980) presented mortality across the entire age range was eight parameter non-linear models. Krishnan and Jin
(Krishnan et al. 1993) fitted the Pareto distribution on national data of Canada for studying distribution of infant deaths. Singh (Singh et al 2011) discussed the number of death of children under the age of five years for fixed parity. Likewise, some of the earlier studies about child mortality by using model. Many researchers used a hyperbolic function to study the infant and child mortality (Keyfitz 1977; Goldblatt 1989; Ronald et al. 1992). Pandey (Pandey et al. 2015) used bio-demographic hazard model to analyze the effects of the biological and socio-economic conditions on the survival of male and female children under-five.

However, no one study has been done to explain the female child death according to educational status of mother through probability model. In this paper, our purpose is to use a new probability model for the number of female child deaths within the first five years of life among the women according to their educational status. The application of the model in the paper is demonstrated through its application to the data from Raebareli district of Uttar Pradesh from Concurrent Assessment of Health \& Family Welfare Programs and Technical Support to District of Uttar Pradesh (CATA 2005).

\section{Construction of models}

\subsection{Model I}

Consider a probability model for the number of female child deaths under-five age, among the women under the following assumption:

i) At any point of time, let $\alpha$ be the probability of female child death among the women and (1- $\alpha)$ be the probability of no female child death among the women.

ii) If $p$ represents the probability of a single female child death among the women, the pattern of female child death among each woman follows the geometric distribution. 
If $\mathrm{x}$ represents the number of female child among women, then $\mathrm{x}$ follows the inflated geometric distribution with probability density function as

$P(x=0)=1-\alpha+\alpha p ; x=0$

$\mathrm{P}(\mathrm{x}=\mathrm{k})=\alpha \mathrm{pq}^{\mathrm{k} ;} \mathrm{k}=1,2,3$

Where $\mathrm{p}+\mathrm{q}=1$

\subsection{Model II}

In the model-I, it has been assumed that number of female child death under five year among the women having fixed probability ' $p$ ' for all but $p$ is effected by a number of factors and therefore assumption of $p$ being a constant for all woman in the population can easily be questioned. Moreover, neither the distribution of $p$ can be directly observed nor data on $\mathrm{p}$ can be obtained. In such a situation, it seems more logical to consider that $p$ is a random variable following some distribution. In other words, it is assumed that probability $\mathrm{p}$ is constant but unknown. It varies from woman to woman and follows a probability distribution $\mathrm{g}(\mathrm{p})$. Here we are assuming that $g(p)$ is beta distribution of first kind with parameters $(a, b)$ The pdf of $p$ i.e. $g(p)$ is given below:

$\mathrm{g}(\mathrm{p})=\frac{1}{\beta(a, b)} \mathrm{p}^{\mathrm{a}-1}(1-\mathrm{p})^{\mathrm{b}-1}$

Where, $0 \leq \mathrm{p} \leq 1 ; \mathrm{a}, \mathrm{b}>0$

Since ' $p$ ' is risk of female child death under five year age group varies from 0 to 1 and beta distribution of first kind is flexible enough. Thus for a given female, the distribution of number of number of female child deatht $X$ out of $n$ born female child among the women follow a geometric distribution and the probability of female child death ' $p$ ' follows beta distribution of first kind with parameters $a$ and $b$, the joint distribution of $X$ and $p$ is given by

$P(X=x, P=p)=P(X=x / p) \times g(p)=p(1-p)^{x}$

And therefore the marginal distribution of $\mathrm{X}$ is given as

$\mathrm{P}[\mathrm{X}=\mathrm{x}]=\frac{\beta(\mathrm{a}+\mathrm{x}, \mathrm{b}+1)}{\beta(\mathrm{a}, \mathrm{b})}$

Where, $x=0,1,2 \ldots \ldots \ldots \ldots \ldots n ; a, b>0$

The above distribution (4) is known as beta-geometric distribution and it is natural extension of geometric model under the consideration for random nature of ' $p$ ' in the population. The parameters a and $b$ are its shape parameters.

\subsection{Estimation}

i) Model I

Inflated geometric distribution has two parameters $\alpha$ and $p$ to be estimated. Let we have

$\mathrm{E}(\mathrm{x})=\frac{\alpha(1-p)}{p}=\bar{x}$

$\mathrm{E}\left(\mathrm{x}^{2}\right)=\frac{\alpha(1-p)(2-p)}{p^{2}}$

\section{Application of the models}

To demonstrate the application of the above discussed model, data have been used from Concurrent Assessment of Health \& Family Welfare Programs and Technical Support to District of Uttar Pradesh (CATA) 2005-06. The survey collected information from currently married women in age group 15-49 on fertility, mortality, family planning and important aspects of reproductive health, etc. Information on all live births to a women and their survival status at the time of survey was also collected.

We assumed that women having no birth during last five year from the survey are to complete their reproductive period. The analysis is based on the information collected from 1151. Women who have lost their female child or not in the last five year and the women who have lost their male child(s) only are considered as zero female child death(s). Maternal education is classified as either educated or uneducated/illiterate. In this paper our main objective is to derive probability model for number female child deaths among women for educational status.

\section{Results and discussion}

In this section, the estimate of parameter and fitting of the models have been discussed. Since, in this study two models are explained for different educational status of women so that after obtaining the estimate of parameters, the estimated frequencies for both the models are obtained. Table 1 is shows that the estimated values of parameters, mean, observed and expected number of total women according to their number of female child death. It can be observed from table 1 that the proposed model describes the pattern of mortality satisfactorily. The corresponding results for women according to different educational status i.e. uneducated and educated women are portrayed in Table 2 and Table 3 respectively. Estimate of parameters, mean, variance, observed and expected number of women are also given in the respective tables.

Table 2 shows expected and observed frequency a distribution of female child deaths according to their mother with no education and both the model seems suitably describe the women. However, the plots of observed and expected frequencies have been drawn to see the adequacy of the model. In this table, the value of $\chi^{2}$ clearly indicates that both the models describe the distribution of number of female child deaths among uneducated women satisfactorily well.

Similarly table 3 , shows that the observed and expected number of educated women according to their female child death. In this table the value of $\chi^{2}$ cannot be calculated due to the degree of freedom comes out to be zero. Though the expected frequencies are very close to the observed frequencies, hence we have calculated K-S statistics to see the suitability of proposed model.

Both the model explains the pattern of female child death satisfactorily. Figure 1, 2 and 3 give the plot of observed and expected frequencies for the number of total women, uneducated women and educated women respectively. From the plot it was found that both the models explain the data set satisfactorily well.

The variability of the data is more captured by both the inflated geometric model and beta geometric model. As it obvious from all the three tables that the inflated geometric model fits well as compare to beta geometric model. So, one may also choose inflated geometric model over beta geometric model in various real-world problems.

$\mathrm{P}$ and $\alpha$ can be estimated by using equation (5) and (6) 


\section{Figures and tables}

Table 1: Expected \& Observed Frequency Distribution of Female Child Deaths among Total Women

\begin{tabular}{|c|c|c|c|}
\hline No of Female child death & Observed number of women & $\begin{array}{l}\text { Inflated geometric } \\
\text { distribution }\end{array}$ & $\begin{array}{l}\text { Beta geometric } \\
\text { distribution }\end{array}$ \\
\hline 0 & 864 & 862.9 & 859.1 \\
\hline 1 & 204 & 205.3 & 212.1 \\
\hline 2 & 55 & 59.3 & 56.5 \\
\hline 3 & 22 & 17.1 & 16.9 \\
\hline 4 & 4 & & \\
\hline 5 & 2 & 6.4 & 6.5 \\
\hline Total & 1151 & 1151 & 1151 \\
\hline Mean $=0.3527$ & $\chi^{2}$ & 1.7224 & 1.9388 \\
\hline Variance $=0.5150$ & $\mathrm{p}$-value (df) & $0.786(2)$ & $0.747(2)$ \\
\hline \multirow{2}{*}{ Estimated value of parameters } & \multirow{2}{*}{$\mathrm{p}$} & $\alpha=0.7110$ & \multirow{2}{*}{$\begin{array}{l}a=9.2438 \\
b=27.2060\end{array}$} \\
\hline & & $\mathrm{p}=0.8679$ & \\
\hline
\end{tabular}

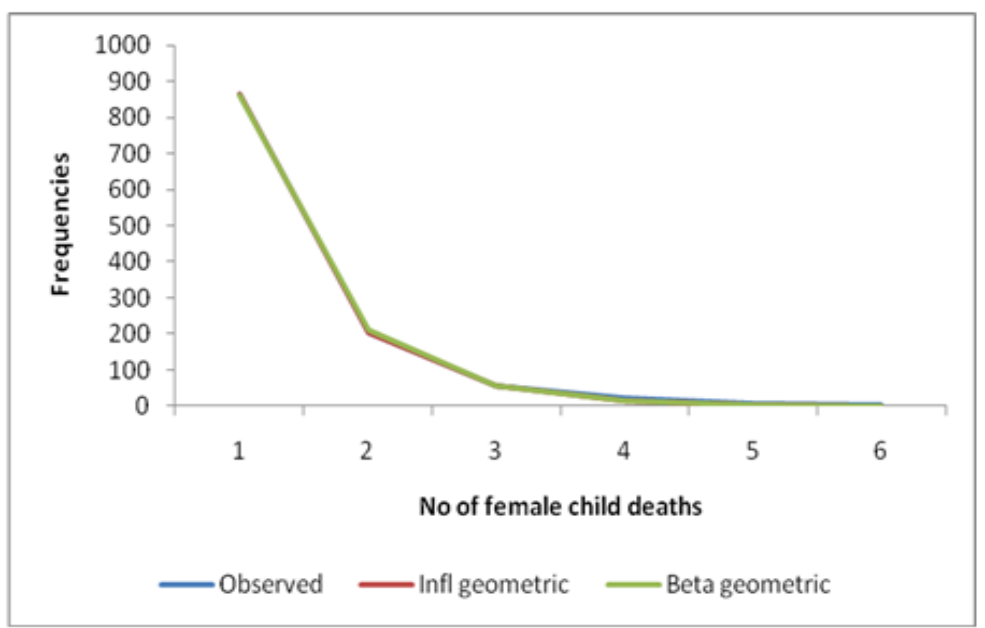

Fig. 1: Expected \& Observed Frequency Distribution of Female Child Deaths among Total Women.

Table 2: Expected \& Observed Frequency Distribution of Female Child Deaths among Women with No Education.

\begin{tabular}{|c|c|c|c|}
\hline No of Female child death & Observed number of women & $\begin{array}{l}\text { Inflated geometric } \\
\text { distribution }\end{array}$ & $\begin{array}{l}\text { Beta geometric } \\
\text { distribution }\end{array}$ \\
\hline 0 & 573 & 571.2 & 594.1 \\
\hline 1 & 154 & 156.0 & 146.7 \\
\hline 2 & 45 & 47.8 & 39.1 \\
\hline 3 & 18 & 14.6 & \multirow{3}{*}{16.2} \\
\hline 4 & 4 & \multirow{2}{*}{5.9} & \\
\hline 5 & 2 & & \\
\hline Total & 796 & 796 & 796 \\
\hline Mean $=0.40703$ & $\chi^{2}$ & 0.9705 & 5.7752 \\
\hline Variance $=0.60065$ & p-value (df) & $0.9142(2)$ & $0.1230(1)$ \\
\hline & & $\alpha=0.9222$ & $\mathrm{a}=17.0930$ \\
\hline Estımated value of parameters & $\mathrm{p}$ & $\mathrm{p}=0.6937$ & $\mathrm{~b}=42.9941$ \\
\hline
\end{tabular}

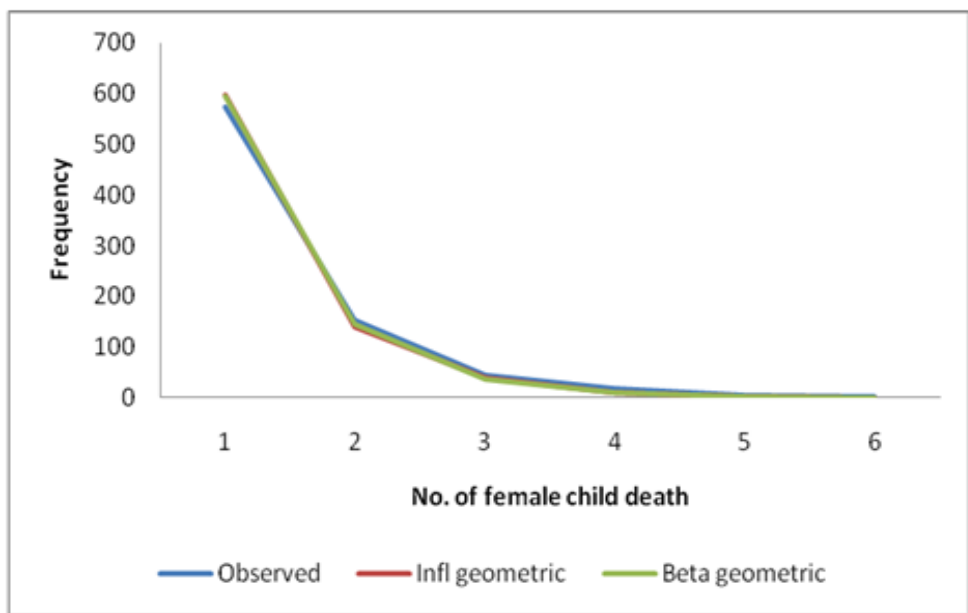

Fig. 2: Expected \& Observed Frequency Distribution of Female Child Deaths among Women with No Education. 
Table 3: Expected \& Observed Frequency Distribution of Female Child Deaths among Women with Education

\begin{tabular}{|c|c|c|c|}
\hline No of Female child death & Observed number of women & $\begin{array}{l}\text { Inflated geometric } \\
\text { distribution }\end{array}$ & $\begin{array}{l}\text { Beta geometric } \\
\text { distribution }\end{array}$ \\
\hline 0 & 291 & 290.3 & 289.9 \\
\hline 1 & 50 & 51.0 & 51.9 \\
\hline 3 & 10 & 13.7 & 13.1 \\
\hline 4 & 4 & & \\
\hline Total & 355 & 355 & 355 \\
\hline Mean $=0.23098$ & & $\mathrm{D}=0.001895$ & $\mathrm{D}=0.003036$ \\
\hline Variance $=0.3015$ & & $P(0.05)=0.07218$ & $\mathrm{P}(0.01)=0.08651$ \\
\hline \multirow[t]{2}{*}{ Estimated value of parameters } & & $\alpha=0.860948$ & $a=7.8526$ \\
\hline & & $\mathrm{p}=0.788462$ & $\mathrm{~b}=34.9963$ \\
\hline
\end{tabular}

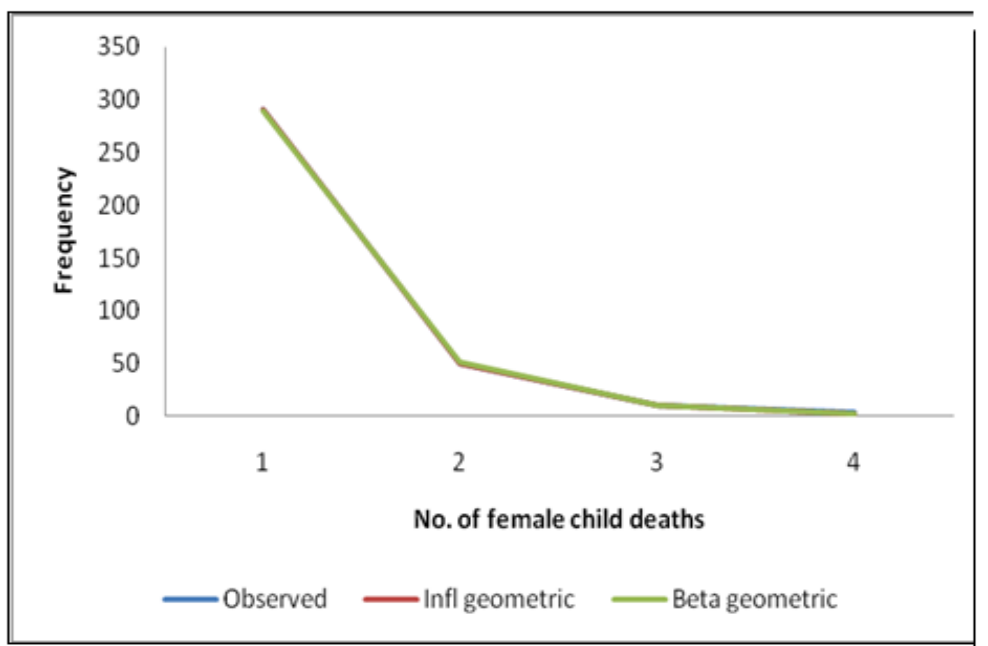

Fig. 3: Expected \& Observed Frequency Distribution of Female Child Deaths among Women with Education.

\section{References}

[1] Sawyer, C. C. (2012). Child mortality estimation: estimating sex differences in childhood mortality since the 1970s. PLoS Med, 9(8), e1001287. https://doi.org/10.1371/journal.pmed.1001287.

[2] Arokiasamy, P. (2004). Regional patterns of sex bias and excess female child mortality in India. Population (english edition), 833-863. https://doi.org/10.2307/3654897.

[3] Tabutin, D., \& Willems, M. (1995). Excess female child mortality in the developing world during the 1970s and 1980s. Population Bulle tin of the United Nations, 39, 45-78.

[4] Papageorgiou, C., \& Stoytcheva, P. (2008). Education Inequality among Women and Infant Mortality: A cross-country empirical investigation.

[5] Cutler, D. A. Deaton and A. Lleras-Muney (2006). "The Determinants of Mortality," Journal of Economic Perspectives 20, 97-124. https://doi.org/10.1257/jep.20.3.97.

[6] Hill A.G. and Devid H.P. (1989). "Measuring Child Mortality in the Third World, in N. Sources and N Approaches, eds," 'IUSSP proceeding of international conference, New Delhi, India.

[7] Pathak KB, Pandey A, Mishra US (1991) On Estimating current Levels of Fertility and Child Mortality from the Data on Open Birth Interval and Survival Status of the last Child, Janasamkhya, 9, 15-24.

[8] Renshaw, A. E. (1991), Actuarial graduation practice and generalized linear and nonlinear models. J. Inst. Act, 118: 295-312. https://doi.org/10.1017/S0020268100019454.

[9] Pandey K.K., Pradip Kumar \& Singh R. D., (2016). A Probability Model for Estimating Under-Five Mortality among Women for Fixed Parity in India. Elixir International Journal. 99 (2016) 4319943201.

[10] Heligman, L. and Pollard, J. H., (1980). Age pattern of mortality. Journal of Institute of Actuaries, 107: 49-80. https://doi.org/10.1017/S0020268100040257.

[11] Krishnan, P. and Jin, Y., (1993). A statistical model for infant mortality. Paper presented at the IUSSP Meeting, Montreal, Canada, August 25- September 1, 1993.

[12] Singh, K.K., \& Singh, B.P. (2011). A probability model for number of child deaths for fixed parity. Demography India, 40(2), 55-68.

[13] Goldblatt P.O. (1989). Mortality by social class, 1971-85. Population Trends, No. 56, Summer.

[14] Ronald D. Lee and Lawrece R. (1992) Carter, 'Modelling and Forecasting U.S. mortality', Journal of American Statistical Association, $87,659-675$.
[15] Keyfitz N. (1977). Applied Mathematical Demography’, John Wiley, New York.

[16] Pandey, K.K. and Lhungdim H. (2015). Sex differential in under-five mortality in India: A regional analysis. Prajna, Vol 60(2), 75-83.

[17] Pradesh, B. F. U. (2005). 2007. Concurrent assment of Healthand Family Welfare Programme and Technical Assistance to Districts of Uttar Pradesh. Editor, JV Singh, Department of Community Medicine, KG Medical University, Lucknow, India. 